\title{
RESEÑA BIOGRÁFICA DEL DR. JORGE LEV JOSELEVICH
}

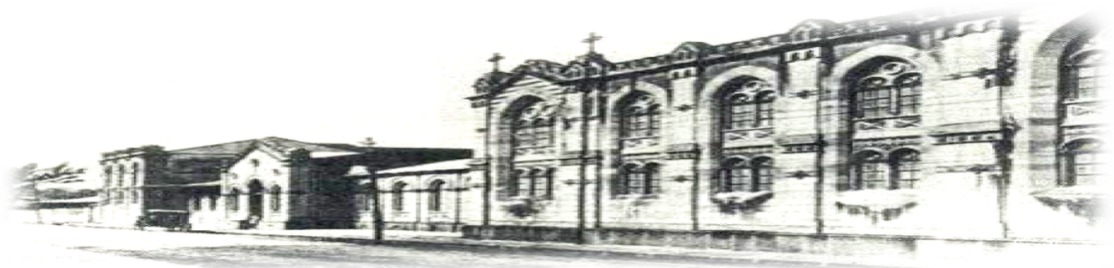

Hospital San quan de Dios, San José. Costa Rica. Fundado en 1845

\section{Luis Fernando Briceño Rodríguez}

Recibido: 22/07/2013

Aceptado: $\quad 14 / 08 / 2013$

HSJD

Luis Fernando Briceño Rodríguez ${ }^{1}$

\begin{abstract}
${ }^{1}$ Ex-Miembro Sección de Medicina - Hospital San Juan de Dios. Profesor Asociado Universidad de Costa Rica (pensionado). Correo electrónico: 1briceno@,racsa.co.cr
\end{abstract}

El doctor Jorge Lev Joselevich fue Profesor Instructor de La Escuela de Medicina de la Universidad de Costa Rica en el Hospital San Juan de Dios.

Nació en Cartago el 17 de febrero de 1933 y falleció en San José el 23 de abril del 2007, a la edad de setenta y cuatro años.

Realizó su educación primaria en la Escuela Buenaventura Corrales y su educación secundaria en el Liceo de Costa Rica.

Llevó a cabo estudios de Farmacia en la Universidad de Costa Rica (UCR) de 1950 a 1951, pero su pasión y su deseo de ser médico le llevó a Argentina, donde realizó sus estudios de Medicina en la Universidad de Buenos Aires.

Del libro El Médico de Noah Gordon, que el doctor Lev nos obsequió, hacemos referencia a las siguientes frases:
“ ¡Sentir que a alguien se le escapa la vida pero que con tus actos puedes devolvérsela! Ni siquiera un rey tiene tanto poder.

\section{Selectos...}

¿Podría aprender más? ¿Cuánto era posible aprender? ¿Cómo será - se preguntó - aprender todo lo que puede enseñarse?

Por primera vez reconoció el deseo de hacerse médico.

¡Luchar verdaderamente con la muerte!’”.

El doctor Lev se graduó como Médico en la Universidad de Buenos Aires en 1960 y se incorporó al Colegio de Médicos y Cirujanos de Costa Rica ese mismo año.

Ingresó en 1961, como Médico Interno al Hospital San Juan de Dios (HSJD); donde 
también llevó a cabo su Residencia en Medicina Interna.

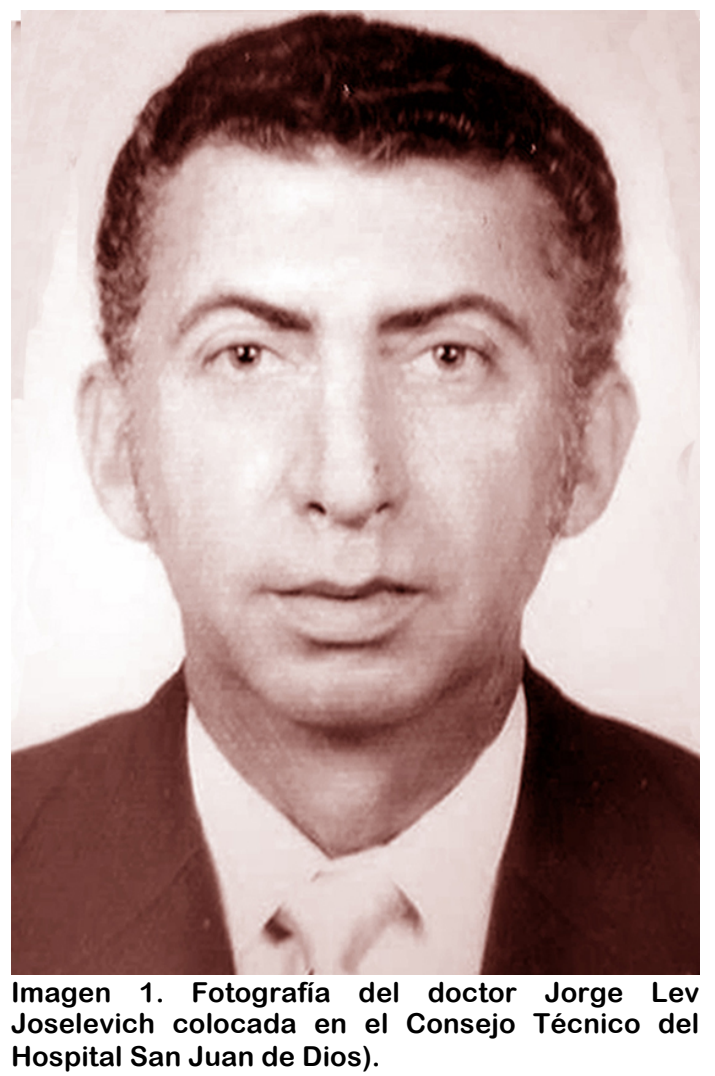

Posteriormente realizó estudios de posgrado en Alergología e Inmunología en la Universidad Nacional Autónoma de México - Distrito Federal.

Fue nombrado Asistente Especialista en Medicina Interna del HSJD a partir de 1965, y Jefe de Clínica del Servicio de Medicina Interna No 2 de 1968 a 1981, habiendo llegado a ser Jefe de Servicio de 1981 a 2005.

Fue Profesor de la Cátedra de Medicina durante treinta y nueve años.

Jorge Lev fue un ser humano justo y honesto, que supo defender con firmeza y valentía sus elevados y definidos principios.

Siempre fue leal y consecuente con sus valores.

Fue un motivador del análisis y discusión de la Medicina Interna al lado del enfermo, "al pie de la cama".
Durante más de cuatro décadas, el hospital fue su vida y disfrutaba el ambiente que él supo crear, su servicio de Medicina Interna, del cual estaba "orgulloso".

Rememorando nuevamente el libro de Gordon, describimos:

"A medida que transcurrían las estaciones, un solo detalle permaneció constante: el sentido complementario, la sensibilidad de sanador, nunca le abandonó. Tanto si cabalgaba en solitario en medio de la noche para acercarse al lecho de un enfermo, como si por la mañana entraba deprisa en el atestado dispensario, siempre sentía el dolor del prójimo. Sin detenerse ante nada para combatirlo, nunca dejó de sentir una oleada de prodigiosa gratitud por haber sido elegido y porque al aprendiz le hubiese sido dada la oportunidad de ayudar y servir".

Durante su vida profesional, Jorge Lev fue un verdadero Médico, un clínico de altos quilates y un excelente Internista.

El doctor Jorge Lev no sólo fue Jefe de su Servicio, sino que, manteniendo el respeto, se caracterizó por ser con todos sus compañeros un verdadero amigo, con su forma jovial, sincera y verdadera de ser, enseñando el verdadero valor de la amistad y por ende de la sinceridad.

Asistía siempre a las presentaciones de los trabajos de graduación del Posgrado de Medicina Interna en su calidad de Jefe de Servicio de Medicina Interna, y como un Internista apasionado, fue un crítico entusiasta, satisfecho por las investigaciones realizadas por los Médicos Residentes.

De todos quienes le conocimos y compartimos la Medicina Interna se ganó admiración y respeto. 